\title{
O Lixo e a Água na Microrregião do Vale do Açu/RN
}

Neste artigo buscamos mostrar o processo de destinação final dos resíduos sólidos (lixo) na microrregião do Vale do Açu/RN e como essa prática inadequada é capaz de comprometer os reservatórios e mananciais de agua no entorno dos lixões, uma vez que o vale açuense é detentor das maiores reservas hídricas dentre os 147 municípios que integram o Comitê da Bacia Hidrográfica do Rio Piancó-Piranhas-Açu (CBH-PPA). As determinações da Política Nacional de Resíduos Sólidos (PNRS) e as ações do Consórcio Intermunicipal de Saneamento Básico do Vale do Açu não tem sido suficientes para avançar no tratamento ambientalmente adequado do lixo. A falta de integração entre as políticas do Estado brasileiro, que tratam dos respectivos temas, o lixo e água seguem misturados, ameaçando poluir e contaminar as águas e os solos da microrregião. A disposição final do lixo nesse espaço geográfico ocorre nos lixões a céu aberto, próximos aos reservatórios e mananciais. $O$ trabalho consistiu em revisão bibliográfica, pesquisa documental e de campo, com visitas aos municípios do Vale do Açu, à procura de dados primários e secundários. Conclui-se que, para resolver o problema do tratamento do lixo de forma eficaz, a ponto de não comprometer a contaminação das águas, é imprescindível a implantação do consórcio público, a construção de um aterro sanitário, apoio técnico e financeiro aos municípios e aos catadores de materiais.

Palavras-chave: Água; Lixo; Vale do Açu.

\section{The Garbage and Water in the Microregion of the Açu Valley/RN}

In this article we seek to show the process of final disposal of solid waste (garbage) in the microregion of Vale do Açu / RN and how this inadequate practice is capable of compromising the reservoirs and water sources around the dumps, since the Açu valley is holder of the largest water reserves among the 147 municipalities that make up the Piancó-Piranhas-Açu River Basin Committee (CBH-PPA). The determinations of the National Solid Waste Policy (PNRS) and the actions of the Intermunicipal Consortium for Basic Sanitation in Vale do Açu have not been sufficient to advance the environmentally appropriate treatment of waste. The lack of integration between the policies of the Brazilian State, which deal with the respective themes, garbage and water are still mixed, threatening to pollute and contaminate the waters and soils of the micro-region. The final disposal of waste in this geographic space takes place in open-air dumps, close to reservoirs and water sources. The work consisted of bibliographic review, documentary and field research, with visits to the municipalities of Vale do Açu, looking for primary and secondary data. We conclude that in order to solve the problem of waste treatment effectively, to the point of not compromising water contamination, it is essential to set up a public consortium, build a sanitary landfill, provide technical and financial support to municipalities and waste pickers of materials.

Keywords: Water; Garbage; Açu Valley.

Topic: Planejamento, Gestão e Políticas Públicas Ambientais

Reviewed anonymously in the process of blind peer.
Received: 24/04/2021

Approved: 25/05/2021

Raimundo Inácio da Silva Filho (ib)

Universidade do Estado Rio Grande do Norte, Brasil

http://lattes.cnpq.br/9652759340859945

http://orcid.org/0000-0001-7567-4171

raimundofilho@uern.br

\section{Francisco Ringostar Pinto (ib}

Universidade do Estado Rio Grande do Norte, Brasil

http://lattes.cnpq.br/5976373380873229

http://orcid.org/0000-0002-8723-834X

chicopintoprofessor@gmail.com

\section{Referencing this:}

SILVA FILHO, R. I.; PINTO, F. R.. Índice de temperatura e umidade para o desenvolvimento da avicultura no Nordeste de Mato Grosso. Revista

DOI: 10.6008/CBPC2179-6858.2021.005.0049 


\section{INTRODUÇÃO}

A preocupação com o tratamento adequado do lixo não é recente. Kautsky (1998), em fins do século XIX, já comentava sobre a agricultura moderna e recomendava a utilização dos dejetos das cidades para a recomposição do solo. Em meados da década de 1970, o físico Capra (2002) também havia conclamado a opinião pública a exercer pressão sobre a indústria para que a mesma desenvolvesse uma tecnologia adequada de tratamento e reciclagem de produtos residuais, uma vez que a produção de lixo só tem crescido nas últimas décadas com o advento da industrialização, da urbanização e do consumo (SILVA FILHO, 2006).

De certo modo é imprescindível o tratamento ambientalmente adequado dos resíduos sólidos, uma vez que o "lixo é o produto final de toda ação de consumo" (BAUMAN, 2010). Com efeito, sabe-se que a disposição ambientalmente inadequada do lixo é prejudicial à sociedade humana e à natureza. Estudos realizados por Alves (2017) destacam que "a presença dos resíduos sólidos, ou lixo em locais inadequados podem trazer grandes transtornos à sociedade e contaminações ambientais". Outros destacados pesquisadores têm nos alertado sobre o tema, conforme revelam Waldman (2010), Pereira Neto (2007), Philippi Jr (2005) e Calderoni (2003).

Buscando avançar nessa matéria, em agosto de 2010, o governo federal sancionou a lei 12.305, que institui a Política Nacional de Resíduos Sólidos (PNRS), que dispõe sobre seus princípios, objetivos e instrumentos, assim como sobre as diretrizes relativas à gestão integrada e ao gerenciamento de resíduos sólidos, incluindo os perigosos, às responsabilidades dos agentes geradores e do poder público e aos instrumentos econômicos aplicáveis (BRASIL, 2010).

Todavia, apesar dos avanços da PNRS, o Brasil não tem conseguido ir adiante nesse problema. Prova disso é que segundo o "Panorama dos resíduos sólidos no Brasil 2000", produzido pela Associação Brasileira de Empresa de Limpeza Pública e Resíduos Especiais - ABRELPE (2020) revela que 40,5\% dos municípios brasileiros encaminham seus resíduos para locais impróprios. Ou seja, dos 5.570 municípios, 1.552 ainda destinam os resíduos sólidos urbanos (RSU) para locais inadequados (aterros controlados e lixões), conforme mostra a geografia regional brasileira dos lixões: Norte $(64,7 \%)$; Nordeste $(67,4 \%)$; Centro-Oeste $(58,7 \%)$; Sudeste $(27,3 \%)$ e Sul $(29,4 \%)$. Embora a destinação final não seja ideal, nas regiões Norte e Nordeste do país a situação é mais crítica.

Nessa mesma linha de preocupação a pesquisa Cempre-Review 2019, realizada pelo Compromisso Empresarial para a Reciclagem - CEMPRE (2019) identificou que apenas 1.227 dos 5.570 municípios brasileiros operam programas de coleta seletiva. No Rio Grande do Norte (RN), por não ser exceção à regra geral, a maioria dos municípios desse Estado despeja os seus resíduos sólidos em lixões a céu aberto e a reciclagem de materiais não tem sido objeto de prioridade pelas prefeituras. Apenas a capital (Natal), dos 167 municípios, opera programa de coleta seletiva (CEMPRE, 2019), com ações de apoio às associações e cooperativas de catadores.

Na microrregião do Vale do Açu/RN, por sua vez, a destinação final ambientalmente adequada do lixo e o reaproveitamento de materiais são inexistentes, pois, nenhum município possui "oficialmente" 
programa de coleta seletiva. Só recentemente o município de Assú construiu um aterro controlado, noutro espaço. O reaproveitamento dos materiais recicláveis ocorre por conta dos próprios catadores nas ruas e nos lixões. Com efeito, o tratamento inadequado do lixo nesse espaço microrregional se torna ainda mais preocupante já que esses municípios integram o Comitê da Bacia Hidrográfica do Rio Piancó-Piranhas-Açu ${ }^{1}$, uma vez que os maiores reservatórios hídricos do RN estão situados nessa microrregião, considerando àqueles com capacidade superior a $10 \mathrm{hm}^{3}$ (ANA, 2010).

Visando solucionar essa problemática estadual, sob as orientações da PNRS, o governo do Estado do RN instituiu, seguindo também as determinações da lei no 11.107, de 6 de abril de 2005 (BRASIL, 2005), o ordenamento territorial dos Consórcios Regionais de Saneamento Básico do Vale do Açu e o Plano Estadual de Gestão Integrada de Resíduos Sólidos do Rio Grande do Norte - PEGIRS/RN (SEMARH, 2012).

Apesar disso, uma década após a criação do Consórcio Regional de Saneamento Básico do Vale do Açu, as determinações da PNRS, cujo prazo final para se ajustar às normas nela contidas caducou em agosto de 2014, continuam sem operacionalização. Pelo exposto percebe-se haver uma larga dissociação dos entes municipais, estaduais e federal nesse tema e noutros assuntos correlatos, como é o caso dos recursos hídricos. Parece que além das dificuldades enfrentadas (de natureza geográfica, política, econômica, cultural, ambiental, educacional e prioritária) nota-se ausência de sintonia entre as políticas do Estado brasileiro. Um exemplo disso é o que pode ser observado na lei 9.433 de 8 de janeiro de 1997, que institui a Política Nacional de Recursos Hídricos - PNRH, no Art. 2으, Inciso I, em que afirma: "assegurar à atual e às futuras gerações a necessária disponibilidade de água, em padrões de qualidade adequados aos respectivos usos" (BRASIL, 1997).

Igualmente ao tratar das competências e "Da Ação do Poder Público", o Art. 31, da referida lei, diz que: "Na implementação da Política Nacional de Recursos Hídricos, os Poderes Executivos do Distrito Federal e dos municípios promoverão a integração das políticas locais de saneamento básico, de uso, ocupação e conservação do solo e do meio ambiente com as políticas federal e estaduais de recursos hídricos" (BRASIL, 1997). Por conseguinte, o Art. 225, da Constituição Federal de 1998, assegura que: "Todos têm direito ao meio ambiente ecologicamente equilibrado, bem de uso comum do povo e essencial à sadia qualidade de vida, impondo-se ao Poder Público e à coletividade o dever de defendê-lo e preserválo para às presentes e futuras gerações". Ora, aqui nitidamente percebe-se, embora exista a intencionalidade do querer fazer, que as políticas do Estado que tratam dos respectivos temas não se articulam entre si, nem tampouco levam em conta os diferentes atores sociais, das diferentes esferas.

Na relação do lixo com a água, por exemplo, é perceptível a ausência de diálogo mútuo entre esses temas. Esse distanciamento tem feito com que o lixo esteja junto com a água em função da precarização de tratamento ambiente adequado. Paradoxalmente, eles continuam separados por falta de harmonia entre os diferentes entes públicos (União, Estado e Municípios), uma vez que se trata de políticas públicas² relevantes para a sociedade e que não deveriam ser administradas isoladamente.

\footnotetext{
${ }^{1}$ O Comitê da Bacia Hidrográfica do Rio Piancó-Piranhas-Açu (CBH-PPA) é resultado do interesse manifesto pelos estados do RN e PB, gerando sua criação através de Decreto Presidencial de 29 de novembro de 2006 . O CBH-PPA é composto por 147 municípios de dois estados da região Nordeste, sendo 102 do estado da Paraíba (PB) e 45 do Rio Grande do Norte (RN). A bacia hidrográfica do rio Piancó-Piranhas-Açu abrange um território de $42.900 \mathrm{~km}^{2}$ distribuído entre esses estados onde vivem aproximadamente 1.552 .000 mil habitantes.
} 
Cabe destacar, que embora o governo federal tenha sancionado a lei 14.026, de 15 de julho de 2020, em que fora atualizado "o marco legal do saneamento básico e alterado a lei no 9.984, de 17 de julho de 2000, para atribuir à Agência Nacional de Águas e Saneamento Básico (ANA) competência para editar normas de referência sobre o serviço de saneamento" (BRASIL, 2020), ainda não é possível observar avanços concretos nesses temas.

Além dessas questões, que tem dificultado a eficácia das ações no tratamento ambientalmente adequado do lixo, nos deparamos com um modo de "vida líquida" (vida precária e de consumo) num mundo "líquido-moderno", em que as realizações são efêmeras (BAUMAN, 2009). Isso agrava ainda mais o problema uma vez que o consumo atua em proporção crescente. De fato, na atual sociedade o consumo e o lixo são inseparáveis, conforme relata Bauman (2009):

O lixo é o principal e comprovadamente o mais abundante produto da sociedade líquidomoderna de consumo. Entre as indústrias da sociedade de consumo, a de produção de lixo é a mais sólida e imune a crises. Isso faz da remoção do lixo um dos dois principais desafios que a vida líquida precisa enfrentar e resolver. $O$ outro é a ameaça de ser jogado no lixo. Em um mundo repleto de consumidores e produtos, a vida flutua desconfortavelmente entre os prazeres do consumo e os horrores da pilha de lixo.

Como agravante dessa realidade, ao tratar de "uma globalização perversa", Santos (2013) enfatiza:

Neste mundo globalizado, a competitividade, o consumo, a confusão dos espíritos constituem baluartes do presente estado de coisas. A competitividade comanda nossas formas de ação. $O$ consumo comanda nossas formas de inação. $E$ a confusão dos espíritos impede o nosso entendimento do mundo, do país, do lugar, da sociedade e de cada um de nós mesmos.

Para agravar ainda mais o quadro, a transmissão do novo coronavírus (SARS-CoV-2), que teve início na cidade de Wuhan, na China, em dezembro de 2019 e em seguida se transformou em pandemia mundial, passou a ser uma ameaça nos lixões das cidades. Sobre essa questão, Souza (2020, p. 69) afirma:

No Brasil, a gestão e o manejo adequados dos resíduos ainda se configuram como uns dos desafios do saneamento básico, tendo extenso volume ainda sem destinação adequada em valas, lixões e ruas. Conforme a recomendação da Política Nacional dos Resíduos Sólidos (PNRS) (2010) e da OMS (2020), os resíduos hospitalares devem ser incinerados, pois o coronavírus e outros patógenos podem sobreviver por cerca de 72 horas em superfícies, aumentando o risco de espalhamento e contaminação da população, principalmente garis e pessoas que manuseiam coletores.

De certa forma a solução para superar o atual estágio, agravado pela pandemia da Covid-19, se faz necessário que a sociedade faça um grande esforço, uma vez que estamos submetidos a uma "competitividade" sem compaixão, numa cultura de 'síndrome consumista'.

Objetiva-se neste artigo, mostrar que o processo de destinação do lixo na microrregião do Vale do Açu/RN requer ações estratégicas e integradas entre os municípios, uma vez que o espaço microrregional é detentor das maiores reservas hídricas dentre os 147 municípios que integram o Comitê da Bacia Hidrográfica do Rio Piancó-Piranhas-Açu.

Por fim, o presente trabalho é a continuação de nossas pesquisas anteriores, atrelado à pesquisa do presente e para o futuro, sempre atentos às questões ambientais, e, sobretudo, a discussão sobre o processo de degradação e contaminação do lixo em bacias hidrográficas no Vale do Açu e outros espaços regionais do Rio Grande do Norte, pois a nossa preocupação nesse processo de investigação, é apontar políticas públicas de preservação ambiental dos aquíferos, rios, lagos e lagoas, bem como o tratamento 
adequado do lixo que não comprometa os recursos naturais, como no caso da hidrografia.

Acreditamos que a continuidade da pesquisa, por meio desta discussão amparado na revisão teórica e conceitual, bem como o trabalho de campo, servirá de subsídio para pesquisas futuras que visem de forma pertinente, estudar a questão ambiental, como no caso do lixo e a água no Mundo, no Brasil e em nossa região.

\section{METODOLOGIA}

A pesquisa consistiu em mostrar o processo de destinação do lixo na microrregião do Vale do Açu/RN e da ameaça desse a contaminação da água, uma vez que o vale açuense é detentor das maiores reservas hídricas dentre os 147 municípios que integram o Comitê da Bacia Hidrográfica do Rio PiancóPiranhas-Açu. A escolha por esse tema, nesse espaço geográfico, se deu pelo fato de que o Vale do Açu é possuidor das maiores reservas hídricas dentre os 147 municípios (sendo 45 no estado do RN e 102 no estado da PB) que integram o CBH-PPA, conforme ANA (2010). Considerando todos os reservatórios do CBH-PPA, com volume superior a $10 \mathrm{hm}^{3}$, os mesmos possuem capacidade de armazenar $5.487,200 \mathrm{hm}^{3}$ $(100 \%)$.

O Vale do Açu, por sua vez, é possuidor de $2.500,80 \mathrm{hm}^{3}$, o que equivale a $45,6 \%$ da reversa hídrica da referida bacia hidrográfica. Esse dado já revela a necessidade de um olhar mais criterioso quanto ao tratamento e a destinação final dos resíduos sólidos no referido espaço microrregional.

Na revisão bibliográfica, procuramos os mais recentes trabalhos sobre a problemática dos resíduos sólidos, com destaque aos relatórios da ABRELPE (2020), CEMPRE (2019) e SELURB (2019). Quanto aos dados da pesquisa, os mesmos foram obtidos em fontes primárias e secundárias. Trata-se, portanto, de um estudo em que além da revisão bibliográfica e da coleta de dados secundários, compreende visitas aos respectivos locais de destinação final do lixo dos nove municípios da microrregião do Vale do Açu, a saber: Alto do Rodrigues, Assú, Carnaubais, Ipanguaçu, Itajá, Jucurutu, Pendências, Porto do Mangue e São Rafael.

\section{RESULTADOS E DISCUSSÃO}

\section{A microrregião do Vale do Açu}

De acordo com o Instituto Brasileiro de Geografia e Estatística (IBGE, 2010) a microrregião do Vale do Açu é formada geograficamente por nove municípios sendo eles: Alto do Rodrigues, Assú, Carnaubais, Ipanguaçu, Itajá, Jucurutu, Pendências, Porto do Mangue e São Rafael, que juntos ocupam uma área territorial de $4.756,11 \mathrm{~km}^{2}$, o que corresponde a 9,06\% do território do Estado do Rio Grande do Norte (RN), conforme mostra a Figura 01.

Segundo os dados do último Censo do IBGE (IBGE, 2015), a microrregião do Vale do Açu é habitada atualmente por 152.003 pessoas. Desse total, $67 \%$ moram no espaço urbano, enquanto que $33, \%$ vivem no meio rural (AQUINO et al., 2013). 


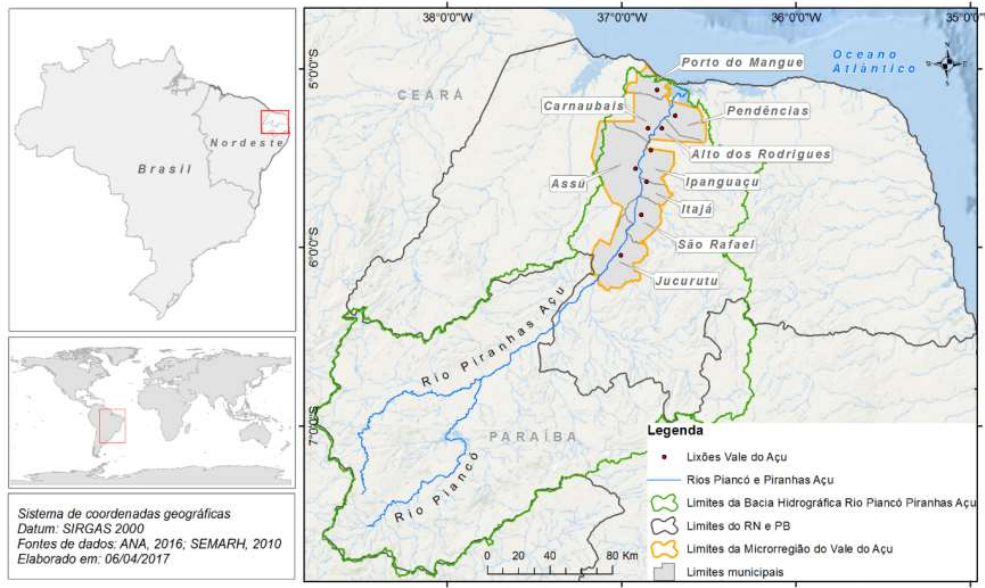

Figura 1: Localização geográfica da microrregião do Vale do Açu, da bacia hidrográfica do rio PiancóPiranha-Açu e dos lixões.

Em termos hidrogeográficos, a microrregião açuense é cortada e banhada pelo Rio PiancóPiranhas-Açu (Figura 01), integra o bioma caatinga e está inserida em plenos domínios do clima semiárido, apresentando temperaturas médias de 28 graus e precipitações anuais normais girando em torno de 700 mm (AQUINO et al., 2013).

\section{O potencial hídrico regional e a ameaça de contaminação}

A microrregião do Vale do Açu é uma das áreas mais privilegiadas em recursos hídricos do Rio Grande do Norte e do Nordeste brasileiro. Destaca-se abundância de água doce e solos férteis. Segundo a ANA (2010), "a Bacia Hidrográfica do rio Piranhas-Açu (Figura 01) é a maior unidade hidrográfica da Região Hidrográfica do Atlântico Nordeste Oriental com $15 \%$ de sua área, que corresponde a uma área de drenagem de 43.681,50 $\mathrm{Km}^{2}$, abrangendo parte dos Estados do Rio Grande do Norte (40\%) e da Paraíba (60\%)". Uma melhor percepção da bacia pode ser vista na descrição feita pala ANA (2010):

O rio Piranhas-Açu nasce na Serra de Piancó no estado da Paraíba e desemboca próximo à cidade de Macau, no Rio Grande do Norte. Como a maioria dos rios do semiárido nordestino, à exceção do rio São Francisco e do Parnaíba, ele é um rio intermitente em condições naturais e é perenizado por dois reservatórios de regularização construídos pelo DNOCS: Curema-Mãe d'Água, na Paraíba, e a barragem Armando Ribeiro Gonçalves, no Rio Grande do Norte. Os principais corpos d'água perenizados na bacia são o rio Piranhas, a partir da regularização promovida pelo reservatório Eng. Ávidos, no trecho que vai até o açude São Gonçalo, na Paraíba, o rio Piancó, este perenizado a partir do reservatório Curema-Mãe D’Água, e o rio Açu, a partir da barragem Armando Ribeiro Gonçalves.

Na microrregião do Vale do Açu, transversalmente ao rio, a abrangência da bacia é constituída por três tipos de áreas: a vazante (leito maior do rio), a várzea (constituída por uma extensa área de material aluvional, localizada as margens do rio) e o tabuleiro (constitui-se de áreas de natureza geológica diversificada entre sedimentares e cristalinos) (AGB, 1961). Ainda, no entorno do rio Piranhas-Açu, existem algumas lagoas, de tamanhos variados, dispostas nas duas margens que funcionam como reguladoras da vasão das águas do rio. De certo modo, o crescimento urbano, aliado às atividades econômicas desenvolvidas nessa microrregião, tem contribuído para alterar o meio ambiente regional. Essa constatação pode ser confirmada no documento: "Termos de referência para a elaboração do plano de recursos hídricos da bacia do rio Piranhas-Açu", organizado pela Agência Nacional de Águas - ANA (2010) que diz: 
A cobertura vegetal da bacia em sua maior parte se encontra bastante antropizada em decorrência da abertura de áreas para exploração agrícola e principalmente pela exploração de lenha como fonte energética para olarias, panificadoras e uso doméstico. Além da perda de biodiversidade, a remoção da vegetação sem critérios de manejo, expõe o solo à ação erosiva das chuvas provocando o transporte de partículas para os corpos hídricos e causando o gradual assoreamento dos reservatórios da região.

Nesse cenário, as águas dos reservatórios existentes - destaque para a Barragem Armando Ribeiro Gonçalves e o leito do Rio Piranhas-Açu - têm sido impactadas com o lançamento de materiais dispostos em locais impróprios, conforme comprova a ANA (2010):

No que tange aos resíduos sólidos, estima-se que cerca de $80 \%$ da população urbana da bacia é atendida por serviço de coleta, valor este inferior à média nacional, que é de $90 \%$. Apesar desse índice de atendimento, verifica-se que grande parte do lixo coletado é disposto de forma inadequada (por ex.: lixões e vazadouros).

Para agravar o quadro, os dados que tratam do Índice de Estado Trófico (IET) para os pontos de monitoramento na bacia, localizados em açudes, constatam níveis elevados de fósforo. A bacia do Rio Piancó-Piranhas-Açu apresenta uma situação onde a grande maioria dos seus trechos observados encontrase na condição crítica. Ao observar a eutrofização dos reservatórios da referida bacia, a ANA (2010) constatou um "consequente crescimento de microalgas e cianobactérias", possivelmente ocasionado, na maioria dos municípios, pelo lançamento de esgotos e disposição inadequada de resíduos sólidos (lixo).

\section{Disposição final ambientalmente inadequada do lixo e suas consequências}

A disposição de resíduos sólidos (lixo) em lixões é prejudicial ao meio ambiente. Além da atração de vetores (insetos e roedores) há risco de fogo, de deslizamentos, de explosões, de espalhamento do lixo pelo vento, da presença de animais, de pessoas e do tempo de decomposição de materiais.

Pinheiro (2000) diz que, quando "o lixo não é disposto e tratado convenientemente, termina por poluir o solo, o ar e a água, contribuindo para proliferação de vetores e de doenças". Além do mais, descrevendo sobre as doenças relacionadas com o lixo, Pereira Neto (2007) mostra que "os microrganismos estão em todos os lugares: no solo, na água doce, na água do mar, no fundo do oceano e no ar". Trata-se de um problema preocupante. Corroborando sobre a ameaça que representa a destinação incorreta do lixo, SELURB (2019) acrescenta que os "lixões, aterros controlados e vazadouros a céu aberto são unidades de recebimento que não têm controle do chorume e do gás emanado da decomposição dos resíduos e nem de materiais perigosos depositados, gerando um grande passivo ambiental".

Todavia, apesar dos avanços da PNRS, o Brasil não tem conseguido ir adiante nesse tema. Prova disso é que segundo o "Panorama dos resíduos sólidos no Brasil 2000", produzido pela Associação Brasileira de Empresa de Limpeza Pública e Resíduos Especiais - ABRELPE (2020) revela que 40,5\% dos municípios encaminham seus resíduos para locais impróprios. Ou seja, dos 5.570 municípios, 1.552 ainda destinam os Resíduos Sólidos Urbanos (RSU) para locais inadequados (aterro controlado e lixões), conforme mostra a geografia brasileira dos lixões: Norte (64,7\%); Nordeste (67,4\%); Centro-Oeste (58,7\%); Sudeste $(27,3 \%)$ e Sul $(29,4 \%)$.

Essa situação é mais preocupante para a destinação para os resíduos da saúde, uma vez que $36 \%$ destes não possui nenhum tratamento prévio, "o que contraria as normas vigentes e apresenta riscos 
diretos aos trabalhadores, à saúde pública e ao meio ambiente" (ABRELPE, 2020). Sobre a preocupação com o resíduo hospitalar, Souza (2020) relata:

Quanto aos resíduos, cita-se o aumento da produção de resíduo sólido hospitalar. A BBC (2020) relata que em Wuhan, o primeiro epicentro da crise da doença na China, por exemplo, a quantidade de lixo cresceu quatro vezes. Borges (2020) aponta que no Brasil, a Associação Brasileira de Recuperação Energética de Resíduos (Abren) alertou por meio de um relatório o Ministério da Saúde sobre o aumento do volume desses resíduos hospitalares gerados pelo novo coronavírus, expondo a população e o meio ambiente aos riscos do material contaminante sem tratamento.

Nessa mesma linha de preocupação a pesquisa Cempre-Review-2019, realizada pelo Compromisso Empresarial para a Reciclagem - CEMPRE (2019) identificou que apenas 1.269 dos 5.570 municípios brasileiros operam programas de coleta seletiva. Isso significa, embora tenha crescido, a partir de 2010, o número de cooperativa e de associações de catadores, bem como, de municípios com programas de coleta seletiva de materiais, estes, por sua vez, representam apenas $17 \%$ dos municípios do país com coleta seletiva em 2018. De fato, é indispensável avançar na política de reaproveitamento dos materiais como forma de reduzir os volumes dos aterros sanitários, eliminação dos aterros controlados e lixões, e geração de ocupação e renda para os catadores.

Ainda, enfatizando o problema dos lixões, Natal, Menezes et al. (2005) relatam que: "Muitas cidades, na tentativa de aliviar o ambiente dos impactos da disposição do lixo, instalam aterros controlados ou lixões em pontos próximos, porém fora do perímetro urbano, encravados no meio rural em áreas menos habitadas". Essa realidade pode ser constatada no Quadro 01.

Quadro 1: Locais de destinação final do lixo no Vale do Açu.

\begin{tabular}{|l|l|r|}
\hline \multicolumn{1}{|c|}{ Municípios } & \multicolumn{1}{c|}{ Local de destinação do lixo } & Distância da sede (km) \\
\hline Alto do Rodrigues & Distrito de Tabatinga & 5,00 \\
\hline Assú & Baixa do São Francisco & 20,00 \\
\hline Carnaubais & Assentamento Santa Luzia / Umbuzeiro & 5,00 \\
\hline Ipanguaçu & Serra da Capivara / Comunidade de Língua de Vaca & 10,00 \\
\hline Itajá & Cabeço/Margem da BR 304 (sentido Natal) & 3,00 \\
\hline Jucurutu & BR 226 - sentido Florânia / Sítio Aroeira II & 3,00 \\
\hline Pendências & Rodovia RN 118 (sentido Macau) & 2,50 \\
\hline Porto Do Mangue & Sítio Porto Pilão / estrada sentido Serra do Mel & 9,00 \\
\hline São Rafael & Soledade II / Pocinhos & 2,00 \\
\hline
\end{tabular}

Fonte: Adaptado de SILVA FILHO (2019).

\section{A contaminação do solo}

Os cuidados quanto à contaminação da terra estão principalmente associados ao contato da água com o solo superficial e subsolo e à preservação da qualidade das águas. As fontes de poluição e contaminação do solo podem ser de origem natural (terremotos, vendavais e inundações); de atividade humana poluição (disposição de resíduos sólidos e líquidos, à urbanização e ocupação do solo, às atividades agropecuárias etc.).

\footnotetext{
${ }^{3}$ Por mais de cinco décadas o destino do lixo em Assú era o lixão. "No município de Assu/RN, o destino dado aos resíduos sólidos é o lixão municipal, que está localizado, aproximadamente, há $150 \mathrm{~m}$ da rodovia estadual RN-016, que liga o município de Assu/RN a Carnaubais/RN, sendo o acesso por uma rua do próprio bairro. O lixão municipal possui uma área de $900 \mathrm{~m}^{2}$. que é alugada à prefeitura municipal e funciona no mesmo local há mais de 50 anos" (ANDRADE et al., 2016). No final de novembro de 2019 a prefeitura municipal iniciou o envio dos resíduos sólidos para o aterro controlado localizado na comunidade de Baixa do São Francisco, cerca de 20 km distante da sede. 
A disposição indiscriminada de resíduos sólidos, principalmente nos lixões, contamina o solo com o processo de liberação de gases e líquidos (chorume ou percolado) e de muitos outros poluentes, que, além de contaminar o solo, contamina também a água e polui o ar. Durante mais de meio século a destinação final dos resíduos sólidos (lixo) da cidade de Assú se dera na comunidade de Lagoa do Ferreiro de Fora.

Sobre o ambiente físico desse espaço, Andrade et al. (2016), relatam:

Nas proximidades do lixão existem 2 (dois) corpos aquáticos, um é a Lagoa do Piató, de grande importância para o município do Assu, que se configura também como o maior lago natural do estado do Rio Grande do Norte, o outro é um pequeno lago em uma propriedade privada. Todos os resíduos do município são coletados pela Prefeitura Municipal, por meio da Secretaria Municipal de Serviços Públicos, e levados para o lixão. Os carros de coleta passam 3 (três) vezes por semana em todos os bairros do município, passando por todas as ruas de cada bairro, inclusive no bairro em estudo -“ Lagoa do Ferreiro". A coleta no município é feita por meio de 9 (nove) veículos (3 (três) compactadores, 3 (três) caminhões e 3 (três) caçambões). Os compactadores são os responsáveis pela coleta do lixo domiciliar e do comércio, os caminhões auxiliam no transporte de resíduos resultante das podas e do corte das árvores, já os caçambões servem para a retirada das metralhas das ruas e obras do município. No lixão, são feitos nivelamentos pelo menos 2 (duas) vezes na semana, ou seja, é feito o reviramento dos resíduos e a terraplanagem, para que os carros de coleta tenham um acesso fácil ao topo da "montanha" de resíduos.

Com todo esse serviço utilizado para o transporte dos lixões, o Lago do Piató, como também outros corpos aquáticos, ficam comprometidos e poluídos com o chorume e outras contaminações do lixo jogado nas margens da lagoa, o que agrava cada vez mais o quadro ambiental desses ambientes hidrográficos, o que acaba por deixar a água num processo gravemente exposto e iminente de contaminação.

\section{A água num processo iminente de contaminação}

A água é indispensável à vida. Segundo Philippi Jr. Et al. (2005) “cerca de 75\% do planeta é constituída de água. Dessa proporção, cerca de $97 \%$ é salgada e está nos oceanos e mares. Outros 2,7\% estão em forma de geleiras, neve, vapor atmosférico e em profundidades inacessíveis, restando 0,3\% para aproveitamento", em diferentes usos. Contudo, essa pequena fração de água está em constante ameaça de poluição e de contaminação, conforme pode ser observado no Quadro 02.

Quadro 2: Principais processos poluidores da água.

\begin{tabular}{|l|l|}
\hline Processos & Definição \\
\hline Contaminação & $\begin{array}{l}\text { Introdução na água de substâncias nocivas à saúde e a espécies da vida aquática (ex.: patogênicos e metais } \\
\text { pesados). }\end{array}$ \\
\hline Assoreamento & $\begin{array}{l}\text { Acúmulo de substâncias minerais (areia, argila) ou orgânicas (lodo) em um corpo d’agua, o que provoca a } \\
\text { redução de sua profundidade e de seu volume útil. }\end{array}$ \\
\hline Eutrofização & $\begin{array}{l}\text { Fertilização excessiva da água por recebimento de nutrientes (nitrogênio, fósforo), causando o } \\
\text { crescimento descontrolado (excessivo) de algas e plantas aquáticas. }\end{array}$ \\
\hline Acidificação & $\begin{array}{l}\text { Abaixamento do pH, como decorrência da chuva ácida (chuva com elevada concentração de íons H+, pela } \\
\text { presença de substancias químicas como dióxido de enxofre, óxidos de nitrogênio, amônia e dióxido de } \\
\text { carbono), que contribui para a degradação da vegetação e da vida aquática. }\end{array}$ \\
\hline
\end{tabular}

Fonte: DESA/UMG (1995).

Nesse mesmo entendimento, Pinheiro (2000) esclarece que “a poluição dos corpos d água pode se dar pelo lançamento direto dos resíduos e carreamento do chorume até as águas superficiais, bem como pela infiltração deste último que termina por atingir os aquíferos subterrâneos". 


\section{Poluição do ar}

O ar atmosférico é, portanto, de vital importância para a sobrevivência dos organismos do planeta, sendo constituído por oxigênio, nitrogênio, dióxido de carbono e outros gases. Para Barros et al (1995) “a poluição do ar é definida como a alteração da qualidade do ar, resultante de atividades que, direta ou indiretamente, prejudicam a saúde, a segurança e o bem-estar da população" criando condições adversas às atividades sociais e econômicas, lançam matéria ou energia em desacordo com os padrões ambientais estabelecidos por lei.

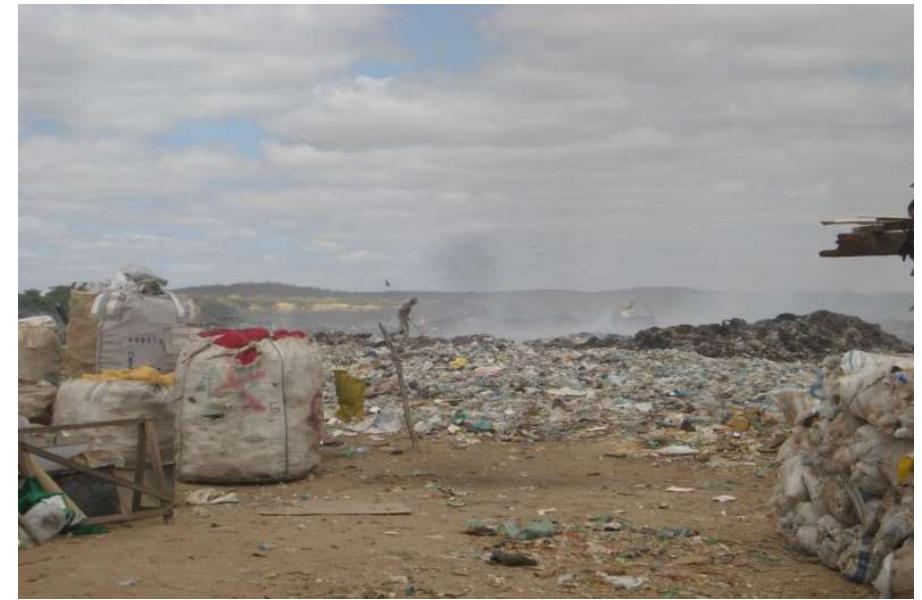

Figura 2: Antigo lixão do município do Assú/RN. Fonte: Silva (2015)

A disposição do lixo em lixões, prática histórica na microrregião do Vale do Açu, é causadora de impacto negativo ao meio-ambiente, uma vez que a maioria dos lixões está situada nas proximidades de reservatórios e sobre mananciais. Referindo-se ao caso do antigo lixão de Lagoa do Ferreiro de Fora, em Assú, Andrade et al. (2016) constatam que:

$\mathrm{Na}$ área do lixão em estudo é perceptível a mudança na fauna e na flora, pois como não há mais a cobertura vegetal local, houve o desaparecimento tanto de espécies de vegetais quanto de animais locais, fazendo-os com que, possivelmente, possam se refugiar em outros locais, havendo um acréscimo no número de garças, urubus e porcos. É perceptível a contaminação do solo pelo chorume. A disposição incorreta dos resíduos altera as características físico-químicas e biológicas do solo, alterando também a sua fertilidade. É o que ocorre no lixão municipal objeto de estudo, onde se pode perceber a coloração escura do solo e, quando é feita a terraplanagem, nota-se a presença do chorume embaixo do solo, além do mau cheiro que emerge, quando os resíduos são revirados. O ar no local é praticamente irrespirável, o odor fétido é muito forte, sem falar na queima dos resíduos que é feita clandestinamente, lançando a grandes alturas uma fumaça negra e fuligem, que encobre parte do bairro, contaminando o ar e prejudicando a saúde das pessoas que ali vivem. Outro agravante é a presença de uma carvoaria dentro do lixão. Todos os corpos aquáticos próximos ao lixão, provavelmente, estão contaminados pelo chorume, pois com a percolação da água no solo, o chorume atinge o lençol freático podendo contaminar as águas superficiais e subterrâneas e, por conseguinte, mudando as características físicoquímicas da água, prejudicando a sua oxigenação.

Nesses locais, além de não existir nenhum tratamento de efluentes líquidos (chorume), são comuns as constantes presenças de pessoas e de animais. O problema do despejo inadequado do lixo nas proximidades dos corpos hídricos é bastante antigo e parece não ter solução no curto prazo. Nota-se um distanciamento entre os entes federativos (União, Estados e municípios). Prova disso, por exemplo, é que a PNRS não dialoga com a PNRH; ambas se "mantém distante" do Consórcio Intermunicipal de Saneamento 
Básico do Vale do Açu uma vez que não se consegue colocar em prática o tratamento ambientalmente adequado do lixo, apesar da existência da Lei 14.026, de 15 de julho de 2020, que "atualiza o marco legal do saneamento básico e altera a Lei no 9.984, de 17 de julho de 2000, para atribuir à Agência Nacional de Águas e Saneamento Básico (ANA) competência para editar normas de referência sobre o serviço de saneamento" (BRASIL, 2020).

Embora seja recente essa modificação na política do saneamento básico, essa ausência de articulação coloca em risco a qualidade da água dos reservatórios e dos mananciais situados no âmbito do Comitê da Bacia Hidrográfica do Rio Piancó-Piranhas-Açu, uma vez que os municípios priorizarão em seus orçamentos os serviços públicos de limpeza urbana e de manejo de resíduos sólidos, abrangendo: a coleta, o transbordo, o transporte e a destinação final.

Cabe salientar que o lixo produzido nos municípios do Vale do Açu é disposto em lixões, muitos deles próximos aos reservatórios ou dos afluentes do Rio Piancó-Piranhas-Açu. Trata-se, portanto, de uma prática comum em toda a microrregião açuense, mas que apesar do seu aparato institucional do Estado, não tem sido capaz de solucionar. Além do despejo a céu aberto, percebe-se a prática da queima do lixo e o lançamento dos esgotos das cidades no leito do rio.

\section{CONCLUSÕES}

Na microrregião do Vale do Açu a destinação ambientalmente adequada do lixo e a articulação com as políticas de Estado que tratam dessa temática são precárias. Não existe cumprimento das determinações da PNRS. Igualmente, criado em 2010, pelo governo do Rio Grande do Norte, o Consórcio Regional de Saneamento Básico do Vale do Açu não tem conseguido avançar na sua operacionalização. Os municípios não conseguem discutir esse tema conjuntamente. A mudança de local de destinação final dos resíduos de Assú, saindo antigo lixão de Lagoa do Ferreiro de Fora para o recém-construído aterro controlado, é um exemplo de como o problema ainda é tratado isoladamente.

O lixo produzido pela população da microrregião do Vale do Açu continua sendo despejado em locais impróprios, nas proximidades de reservatórios e mananciais, contribuindo fortemente para a poluição das águas e contaminação da terra. O processo de eutrofização dos reservatórios da referida bacia é uma realidade constatada, comprometendo a qualidade das águas em função da atividade da indústria têxtil, atividades minerais, esgotos e lixos. Todavia, para enfrentar esse problema de forma eficaz, será indispensável, a retomada dos diálogos acerca da implantação do consórcio público intermunicipal, a construção de um aterro sanitário, o apoio de profissionais técnicos, a disponibilização de recursos financeiros aos municípios, a governança mútua entre os entes da Federação e a implantação de uma nova filosofia educacional para a sociedade. Tal constatação se faz necessário uma vez que nos deparamos com uma forma de vida orientada fortemente para o consumo, o que faz aumentar diariamente a produção de lixo.

Por fim, para que se tenha um novo paradigma de vida será preciso promover uma campanha educacional baseada na filosofia do "consumo solidário e responsável". Sem essas ações dificilmente 
conseguiremos viabilizar, no médio e no longo prazo, o tratamento adequado do lixo, inclusive o reaproveitamento dos materiais recicláveis e a criação de cooperativas de catadores.

\section{REFERÊNCIAS}

ANA. Agência Nacional De Águas. Termos de referência para a elaboração do plano de recursos hídricos da bacia do rio Piranhas-Açu. 2010.

ALVES, J. B.. A face oculta do lixo. Londrina: Mecenas, 2017.

AQUINO, J. R.; SILVA FILHO, R. I.; MIRANDA, M.. A

socioeconomia e o meio ambiente do Vale do Açu no limiar do século XXI. OESTE. Revista do Instituto Cultural do Oeste Potiguar, n.17, p.29-43, 2013.

ANDRADE, A. T. S.; ALCÂNTARA, R. L.. Resíduos sólidos urbanos e impactos socioambientais no bairro "Lagoa do Ferreiro", Assu/RN. Revista Eletrônica em Gestão, Educação e Tecnologia Ambiental: REGET, v.20, n.1, p.16-31, 2016.

ABRELPE. Associação Brasileira Das Empresas De Limpeza Pública E Resíduos Especiais. Panorama dos resíduos sólidos no Brasil, 2020.

AGB. Associação Dos Geografos Brasileiros. A várzea do Açu. São Paulo: AGB, 1961.

BARROS, R. T. V.. Manual de saneamento e proteção ambiental para os municípios. Belo Horizonte: Segrac, 1995.

BAUMAN, Z.. Vida líquida. 2 ed. Rio de Janeiro: Zahar, 2009.

BRASIL. Resolução 001/86. Define as situações e estabelece os requisitos e condições para desenvolvimento de Estudo de Impacto Ambiental - EIA e respectivo Relatório de Impacto Ambiental - RIMA. Brasília: DOU, 1986,

BRASIL. Lei 9.433. Institui a Política Nacional de Recursos Hídricos, cria o Sistema Nacional de Gerenciamento de Recursos Hídricos, regulamenta o inciso XIX do art. 21 da Constituição Federal, e altera o art. 1으 da Lei no 8.001, de 13 de março de 1990, que modificou a Lei 7.990, de 28 de dezembro de 1989. Brasília: DOU, 1997.

BRASIL. Constituição da República Federativa do Brasil. Brasília: DOU, 1988.

BRASIL. Lei 12.305. Institui a Política Nacional de Resíduos Sólidos; altera a Lei no 9.6055, de 12 de fevereiro de 1998; e dá outras providências. Brasília: DOU, 2010.

BRASIL. Lei 14.026. Atualiza o marco legal do saneamento básico e altera a Lei no 9.984, de 17 de julho de 2000. Brasília: DOU, 2020.

CALDERONI, S.. Os bilhões perdidos no lixo. 4 ed. São Paulo: Humanitas, 2003.

CAPRA, F.. O ponto de mutação. São Paulo: Cultrix, 2002.

CBH-PPA. Comitê Da Bacia Hidrográfica Do Rio PiancóPiranhas-Açu. O comitê: trajetória, desafios e avanços do Comitê da Bacia Hidrográfica do Rio Piancó-Piranhas-Açu, 2014.
CEMPRE. Compromisso Empresarial Para Reciclagem, 2009. 2021.

RIO GRANDE DO NORTE. Protocolo de intenções de consórcio público regional de saneamento básico do Vale do Açu. Natal, 2010.

GRUPO INTERDEPARTAMENTAL DE PESQUISA SOBRE EDUCAÇÃO EM CIÊNCIAS. Geração e gerenciamento dos resíduos sólidos provenientes das atividades humanas. 2 ed. Ijuí: Unijuí, 2003.

IBGE. INSTITUTO BRASILEIRO DE GEOGRAFIA E ESTATÍSTICA Cidades, 2015.

KAUTSKY, K.. A questão agrária. Brasília: Instituto Teotônio Vilela, 1998.

DESA/UFMG. Manual de saneamento e proteção ambiental para os municípios. Belo Horizonte, 1995.

NATAL, D.; MENEZES, R. M. T.; MUCCI, J. L. N.. Fundamentos de ecologia humana. In: PHILIPPI JÚNIOR, A.. Saneamento, saúde e ambiente: fundamentos para um desenvolvimento sustentável. Barueri, 2005.

PEREIRA NETO, J. T.. Gerenciamento do lixo urbano: aspectos técnicos e operacionais. Viçosa: Editora da Fundação Getúlio Vargas, 2007.

PHILIPPI JÚNIOR, A.. Saneamento, saúde e ambiente: fundamentos para um desenvolvimento sustentável. Barueri: Manole, 2005.

PHILIPPI JÚNIOR, A.; MARTINS, G.. Águas de abastecimento In: PHILIPPI JÚNIOR, A.. Saneamento, saúde e ambiente: fundamentos para um desenvolvimento sustentável. Barueri: Manole, 2005.

PINHEIRO, S. B.. Os resíduos sólidos urbanos na cidade de Natal e a avaliação ambiental da remediação do lixão de Cidade Nova. Dissertação (Mestrado em Recursos Hídricos e Saneamento Ambiental) - Universidade Federal do Rio Grande do Norte, Natal, 2000.

SANTOS, M.. Por outra globalização: do pensamento único à consciência universal. 23 ed. Rio de Janeiro: Record, 2013.

SECCHI, L.. Políticas públicas: conceitos, esquemas de análise e casos práticos. 2 ed. São Paulo: Cengage Learning, 2015.

SEMARH. Secretaria de estado do meio ambiente e dos recursos hídricos do estado rio grande do Norte. Relatório síntese: plano estadual de gestão integrada de resíduos sólidos do Rio Grande do Norte. Natal: SEMARH, 2012.

SILVA FILHO, R. I.. O lixo em Natal: o potencial sócioeconômico e a nova dinâmica sócio-territorial. Natal: 
Departamento Estadual de Imprensa, 2006.

SELURB. Sindicato Das Empresas De Limpesa Urbana No Estado De São Paulo. Índice de sustentabilidade da limpeza urbana. São Paulo, 2019.

SOUZA, L. P.. A pandemia da COVID-19 e os reflexos na relação meio ambiente e sociedade. Revista Brasileira de Meio Ambiente, v.8, n.4, p.68-73, 2020.
WALDMAN, M.. Lixo: cenários e desafios - abordagens básicas para entender os resíduos sólidos. São Paulo: Cortez, 2010.

A CBPC - Companhia Brasileira de Produção Científica (CNPJ: 11.221.422/0001-03) detém os direitos materiais desta publicação. Os direitos referem-se à publicação do trabalho em qualquer parte do mundo, incluindo os direitos às renovações, expansões e disseminações da contribuição, bem como outros direitos subsidiários. Todos os trabalhos publicados eletronicamente poderão posteriormente ser publicados em coletâneas impressas sob coordenação da Sustenere Publishing, da Companhia Brasileira de Produção Científica e seus parceiros autorizados. Os (as) autores (as) preservam os direitos autorais, mas não têm permissão para a publicação da contribuição em outro meio, impresso ou digital, em português ou em tradução. 